\title{
REDESIGN DE EMBALAGEM: UM ESTUDO SOBRE PRODUTOS IMPRESSOS NAS CAIXAS DE PAPELÁO
}

\section{PACKAGING REDESIGN: A STUDY OF PRINTED PRODUCTS IN CARDBOARD BOXES}

André Schlemmer ${ }^{1}$ Diandra Leandro da Silveira ${ }^{2}$ 


\section{Resumo}

Este artigo teve como objetivo realizar um redesign de embalagem analisando os atuais produtos de caráter sustentável, impressos nas caixas de papelão. Para isso, estão presentes no projeto os conceitos de design de embalagem, sustentabilidade e consumo sustentável, baseados nas metodologias de Mestriner e Löbach para melhorias e soluções no reaproveitamento de embalagem de papelão, além de uma propostas para identidade visual, conceituação e sugestão de reúso. O redesign de embalagem foi dividido em quatro etapas: a aplicação de um questionário; a análise dos 10 pontos-chave de Mestriner; o desenvolvimento da identidade e das estratégias de divulgação, e por fim a análise das funções. Como resultado, desenvolvemos um novo conceito para reúso, que garantiu a coerência dos objetivos propostos, conferindo assim uma nova marca, melhorias e soluções para embalagens de papelão.

Palavras-Chave: Design de produto; Redesign de embalagem; Reaproveitamento

\section{Abstract}

This paper aims to conduct a packaging redesign analyzing the current sustainable feature of products, printed on the cardboard boxes. Therefore, it is present in project the concepts of packaging design, sustainability and sustainable consumption, based on methodologies for Mestriner and Lobach to improvements and solutions in reutilization for cardboard packaging, in addition to a proposal for visual identity, conceptualization and reuse suggestion. The packaging redesign was divided in four steps: application of a questionnaire; analysis of the 10 key points Mestriner; the identity development, advertisement strategies and finally, analysis of functions. As a result, we developed a new concept for reuse, which ensured a consistency of the proposed objectives, improvements and solutions to cardboard packaging.

Keywords: Product design; Packaging redesign; Reuse

ISSN: 1808-3129
${ }^{1}$ André Schlemmer

Departamento de Pesquisa da UnC

schlemmer.andre@gmail.com
2 Diandra Leandro da Silveira

UnC - Campus Rio Negrinho

Rio Negrinho, SC, Brasil

diandraleandros@gmail.com 


\section{INTRODUÇÃO}

O Presente artigo foi produzido através de um projeto da disciplina de Concepção e Lançamento de Novos Produtos da $8^{a}$ fase do curso de Design da Universidade do Contestado - Campus Rio Negrinho.

Com o intuito de se tornar aplicável e mercadológico, o estudo foi inserido na empresa Meu Móvel de Madeira ${ }^{1}$, que no ano de 2009, em sinergia com as questões de responsabilidade ambiental, inovou em suas embalagens, incluindo desenhos planificados conforme ilustra a figura 01, que poderiam ser reaproveitados pelos clientes através do recorte e montagem, tornando-se assim uma embalagem reutilizável com caráter sustentável.
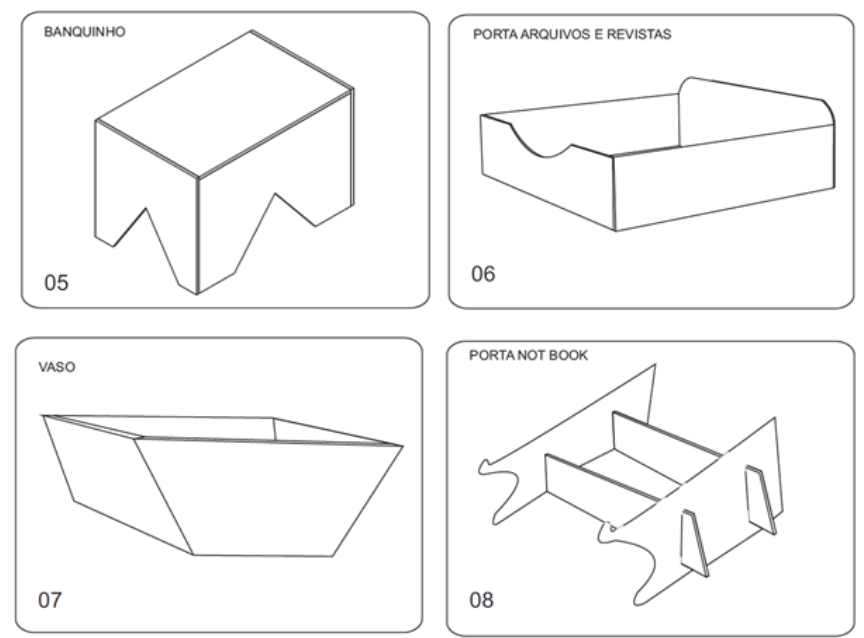

Figura 01: Embalagens reutilizáveis com desenhos planificados Fonte: Meu Móvel de Madeira (2013)

Outra empresa em destaque é a lkea ${ }^{2}$, considerada uma das maiores no mercado internacional de móveis e decoração, apresenta uma capacidade e experiência para melhorar a qualidade dos produtos e a sustentabilidade ambiental e social, todavia durante nossa pesquisa exploratória, não registramos nenhuma ação de reaproveitamento de suas embalagens, como também, nenhuma outra empresa da região do Planalto Norte Catarinense que reaproveita o interior de suas embalagens, o que motivou a realização do projeto na empresa Meu Móvel de Madeira.

Levando em consideração as abordagens relatadas acima, entendemos que é necessário analisar e desenvolver novas propostas de reaproveitamento da atual embalagem da empresa, com o intuito de expandir a atitude sustentável na sociedade. Diante de uma abordagem do design de embalagem e sustentabilidade, definimos como objetivo principal analisar e desenvolver através do reaproveitamento de embalagem, o redesign do produto impresso nas caixas de papelão.

Para tanto, foi necessário definir um objeto de estudo que utiliza embalagem e acondicionamento de ferragens da empresa Meu Móvel de Madeira. Estudamos os produtos impressos nas caixas de papelão e do acondicionamento das ferragens da Escrivaninha Duna 120. O móvel foi escolhido, pois estava entre os cinco produtos

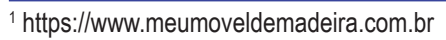

2 http://www.ikea.com 
mais vendidos pela empresa. Através desse fluxo de vendas, conseguimos verificar se a reutilização da embalagem era aprovada pelo consumidor.

Segundo Mestriner (2002, p. 09) a função de uma embalagem é o de "conservar, expor, vender os produtos e finalmente conquistar o consumidor por meio de seu visual atraente e comunicativo". Assim, a embalagem em seu sentido histórico foi uma importante ferramenta para o desenvolvimento do comércio e das cidades.

Para Mozota, Klöpsch e Costa (2003) o design de embalagem está integrado em três diferentes áreas do design:

Design gráfico, no qual o designer modifica ou cria o conjunto gráfico de uma superfície impressa, tal como um rótulo;

Design de produto, ou embalagem orientada para o volume, em que o designer aperfeiçoa as qualidades funcionais da embalagem, melhorando ou simplificando, por exemplo, como o produto é usado pelo consumidor;

Design tridimensional, que é um nível conceitual do design de embalagem, que pode transformar todos os aspectos do produto, tais como modificação de forma, materiais ou sistema de interface de um produto.

O papel do designer, portanto, não se torna importante apenas para vender produtos, mas também para conscientizar sobre os benefícios que podemos adquirir adotando um consumo sustentável no meio em que vivemos. Logo, busca melhorias para si, seus clientes e para o bem estar de todo o planeta (CAMARGO et al., 2007). 


\section{EMBALAGEM E SUSTENTABILIDADE}

A embalagem pode ser considerada o reflexo de uma sociedade, de sua cultura, hábitos, e do seu estágio de desenvolvimento econômico, social e ambiental. Assim, o design de embalagem tem, portanto como finalidade, proteger o produto durante o seu manuseio, armazenar seu conteúdo e auxiliar no transporte e venda.

Para que possamos compreender melhor o universo da embalagem é necessário saber que existem sete tipos de embalagens, dentre elas o vidro, a celulose, o plástico, o metal, a madeira, a embalagem composta e o tecido. Assim, a embalagem escolhida neste projeto se enquadra dentro da matéria-prima conhecida como celulose, e pode ser encontrada sob a forma de cartão - utilizado em embalagens tipo cartuchos, caixas e envelopes, bem como, pode ser encontrada sob a forma de papelão e papelão microondulado - utilizado em embalagens cartonadas e caixas. E por fim, sob a forma de papel - utilizada em embalagens tipo sacos (MESTRINER, 2002). Observamos que ao definir os tipos de embalagem, as indústrias atualmente ocupam a linha de frente nas políticas de sustentabilidade no Brasil, por exemplo, no aproveitamento máximo de matérias-primas, controle rigoroso de produção, gestão de recurso, etc. (ABRE, 2013a).

\section{CONSUMO SUSTENTÁVEL}

A atual abundância dos bens de consumo, produzidos continuamente pelo sistema industrial, é considerada um símbolo do sucesso das economias capitalistas modernas. No entanto, passou a receber uma conotação negativa, sendo objeto de críticas que consideram o termo "consumismo" um dos principais problemas das sociedades industriais modernas (MINISTÉRIO DO MEIO AMBIENTE, 2005).

$O$ atual padrão de consumo dos produtos industrializados, destacando aqueles que necessitam de algum tipo de embalagem, tem como resultado, mais uma forma de degradação do meio ambiente (OLIVEIRA e MORAES, 2007). Aliado a este viés, a ABRE (2013b) define que o "consumo consciente é um processo que começa na escolha do produto e passa pelo seu uso e descarte", onde todas as etapas do consumo podem ser pensadas racionalmente no desenvolvimento de novos produtos para o mercado.

Desta forma, podemos identificar seis características essenciais que devem fazer parte de qualquer estratégia de consumo sustentável, de acordo com a cartilha do Ministério do Meio Ambiente (2005):

1) Deve ser parte de um estilo de vida sustentável em uma sociedade sustentável;

2) Deve contribuir para nossa capacidade de aprimoramento, enquanto indivíduo e sociedade;

3) Requer justiça no acesso ao capital natural, econômico e social para as presentes e futuras gerações;

4) O consumo material deve se tornar cada vez menos importante em relação a 
outros componentes da felicidade e da qualidade de vida;

5) Deve ser consistente com a conservação e melhoria do ambiente natural;

6) Deve acarretar um processo de aprendizagem, criatividade e adaptação.

\section{PROCEDIMENTOS PARA REALIZAÇÃO DO PROJETO}

Os procedimentos metodológicos que envolveram a realização deste projeto, a fim de conhecer e analisar tecnicamente a embalagem e $o$ acondicionamento das ferragens foram divididos em quatro etapas:

1) Aplicação de um questionário;

2) Análise dos 10 pontos-chave de Mestriner;

3) Desenvolvimento da identidade e das estratégias de divulgação;

4) Análise das funções.

A concretização destas 04 etapas visam o desenvolvimento através do reaproveitamento de embalagem, para o redesign do produto impresso nas caixas de papelão da Escrivaninha Duna 120. Na sequência, explicamos em detalhes cada uma das etapas deste projeto:

\section{ETAPA I: QUESTIONÁRIO}

Realizamos a aplicação de um questionário online em parceria com o departamento de marketing da Meu Móvel de Madeira. O questionário foi desenvolvido no Google Drive, pela ferramenta formulário, foi disparado entre os dias 14 e 20 de setembro de 2013, em um e-mail marketing para uma base de 8.792 clientes (que compraram um produto com desenho planificado na embalagem), contendo o link para responder as seguintes perguntas:

1. Você aproveitou a caixa de papelão para montar o produto impresso na embalagem? (questão fechada, podendo optar apenas entre sim e não);

2. Foi útil para você o produto impresso na caixa de papelão? (questão fechada, podendo optar entre uma escala Likert ${ }^{3}$, sendo que 1 significa menos útil e 5 super útil);

3. Se você montou o produto indicado na caixa de papelão, como foi à experiência? (questão fechada, podendo optar entre uma escala Likert sendo que 1 significa uma experiência ruim e 5 uma experiência ótima);

4. Que tipo de produto e/ou objeto gostaria de receber para montar com a caixa que embalou o seu móvel? (questão aberta).

${ }^{3}$ Segundo o site Netquest (2013) a escala Likert é uma escala psicométrica e uma das mais utilizadas em pesquisas quantitativas, pois registra o nível de concordância ou discordância sobre algo. 
Em seguida junto aos resultados, realizamos a análise dos dados para dar continuidade ao projeto de concepção e lançamento do novo produto.

\section{ETAPA II: 10 PONTOS-CHAVE}

No método de Mestriner (2002) existem dez pontos-chave que orientam o design de embalagem, a fim de garantir a consistência dos objetivos propostos pela embalagem. Segue em detalhes cada um destes pontos:

\section{Conhecendo o produto}

Mestriner (2002, p.26) afirma que "a embalagem é expressão e atributo do conteúdo". Para tal é necessário conhecer profundamente o produto, suas características, composição, diferenciais de qualidade, principais atributos e seu processo de fabricação. Para melhor conhecer o produto, realizamos uma visita técnica na empresa fabricante da Escrivaninha Duna 120, bem como, analisamos sua embalagem, esquema de montagem e estrutura através de uma montagem pessoal do móvel.

\section{Conhecendo o consumidor}

Nesta etapa se faz necessário conhecer todas as características do consumidor alvo, seus hábitos e atitudes em relação ao produto e as motivações que levam o público a consumi-lo. Para melhor conhecer o perfil do público consumidor foram compilados dados fornecidos pela empresa, e também foram analisados relatórios do E-bit e Navegg Analytics, fontes de informação sobre o comércio eletrônico no Brasil.

\section{Conhecendo o mercado}

Buscar informações sobre o mercado implica identificar onde o produto está inserido, pois possui características próprias como uma história, dimensões e perspectivas. Para melhor conhecer o mercado de embalagem de papel, papelão e cartão foram realizadas pesquisas e análises de dados disponibilizadas pela ABRE (Associação Brasileira de Embalagem), junto ao IBRE (Instituto Brasileiro de Economia) e a FGV (Fundação Getúlio Vargas). Foram compiladas informações sobre o crescimento, faturamento, expansão e dados que configuram o setor de embalagem no Brasil.

\section{Conhecendo a Concorrência}

Para melhor conhecer a concorrência foram pesquisadas empresas nacionais e internacionais do ramo de móveis e decorações, que reaproveitam suas embalagens de papelão para criar novos produtos com caráter sustentável, utilizando aqui o método de benchmarking ${ }^{4}$ entre as empresas.

${ }^{4}$ Segundo Hilsdorf (2013) benchmarking é uma ferramenta de gestão que consiste na mensuração da atuação de uma organização, permitindo que ela compare sua eficiência com a de outras organizações. 
5. Conhecendo tecnicamente a embalagem a ser desenhada

Conhecer a linha de produção da embalagem, a estrutura dos materiais utilizados, as técnicas de impressão,

os desenhos ou plantas técnicas da embalagem necessitam ser muito bem conhecidas para se obter o máximo

dos recursos. Evitando assim erros que podem vir a prejudicar o projeto no futuro. Para conhecer tecnicamente a embalagem a ser desenhada neste projeto foi realizada uma visita técnica à empresa Nova Embalagens de São Bento do Sul-SC, e posteriormente foram relatados os processos adotados pela empresa.

\section{Conhecendo os objetivos mercadológicos}

Nesta etapa os objetivos da embalagem devem estar alinhados com o marketing da empresa, a sua participação no mercado, seu papel na comunicação e as diretrizes comerciais para nortear o projeto. Para compreender objetivos mercadológicos foi conhecido e condensado junto ao departamento de marketing e a gerente de entretenimento da empresa, os pontos determinantes para explorar, promover e divulgar a nova proposta de redesign de embalagem e soluções para o acondicionamento das ferragens.

\section{A estratégia para o Design}

É importante saber posicionar visualmente o produto de forma que se obtenham vantagens competitivas em relação a seus concorrentes. Para melhor compreender as estratégias orientadas para o design foram coletadas informações junto a empresa e toda a cadeia envolvida na configuração de seu produto final, através de reuniões e conversas com especialistas.

\section{Desenhando de forma consciente}

Para projetar de forma consciente, além de reunir os pontos-chave de Mestriner, buscamos embasar o processo de redesign da embalagem junto à metodologia de Lobäch (2001) que foi adaptada para este projeto conforme os passos a seguir:

Fase da preparação: Análise dos problemas; coleta de informações e análises;

Fase da geração: Produção de ideias e geração de alternativas;

Fase da avaliação: Processo de seleção e avaliação das alternativas;

Fase da realização: Mockups 5 , desenhos técnicos e protótipo.

\section{Trabalho integrado com a indústria}

Para integrar o projeto desenvolvido junto à indústria, buscamos conhecer através de visita técnica realizada na empresa Nova Embalagens, as limitações da indústria, padrões adotados, especificações e detalhes para a

preparação do material, e consequentemente, execução do projeto.

\footnotetext{
5Mockups são modelos em tamanho real de um projeto, usados para demonstrar, avaliar e estudar oportunidade de melhoria no design do projeto. Deve ser
} construída na mesma escala do produto original e deve apresentar pelo menos partes das funcionalidades do projeto 


\section{Revisão do projeto}

Quando a embalagem final chegar ao mercado, o ideal é que o designer realize uma visita a campo para avaliar o resultado final e propor melhorias ou ajustes que possam ser incorporadas às novas produções e reimpressões. Nesta etapa foram levantadas junto a empresa as formas de avaliação que serão adotadas após a execução e implementação do projeto, contendo novas planificações para reaproveitar as embalagens.

\section{ETAPA III: Estratégia de identidade e divulgação}

Aliado ao método de Mestriner (2002) quanto aos objetivos mercadológicos e de estratégia para o design, foram desenvolvidas uma identidade visual para a comunicação da marca, para sua embalagem de caráter sustentável, bem como, quatro mídias para a promoção da marca, comunicação e divulgação da mesma.

\section{ETAPA IV: Análise das Funções}

Segundo Löbach (2001, p. 146) "a análise da função é um método para estruturar as características técnicas funcionais de um produto, que podem ser observadas através de suas qualidades funcionais". Desta maneira, para analisar o redesign da embalagem de caráter sustentável, e do acondicionamento das ferragens utilizamos as análises de função prática, estética e simbólica, segundo Medeiros (2013) define como:

Função prática: é a relação entre um produto e seus usuários que se situa no nível orgânico-corporal, ou seja, satisfazem necessidades fisiológicas do usuário.

Função estética: é a relação entre um produto e seus usuários que se situa no nível dos processos sensoriais, ou seja, a função estética dos produtos é um aspecto psicológico da percepção sensorial durante o uso.

Função simbólica: é a relação entre um produto e seus usuários que se situa no nível espiritual, estimulada pela percepção do objeto, estabelecendo ligações com suas experiências e sensações anteriores.

\section{RESULTADO DO QUESTIONÁRIO}

Constatamos que dos 8.792 clientes que receberam o e-mail marketing, apenas 219 responderam de forma espontânea, sendo assim, por intermédio destes respondentes obtemos os seguintes resultados: 
$72 \%$ dos respondentes aproveitaram a caixa de papelão para montar o produto indicado na embalagem;

$34 \%$ classificaram como muito útil o resultado do produto no seu dia-a-dia, contra $22 \%$ que classificaram como nada úteis, e $20 \%$ classificaram como mediana a utilidade do produto recebido na embalagem;

$44 \%$ dos consumidores classificaram como ótima a experiência da montagem do produto planificado na embalagem de papelão, contra 17\% que classificou como mediana a experiência.

A última pergunta aberta do questionário, possibilitou aos respondentes sugerirem ideias, opiniões, desejos e comentários sobre a interação com a atitude sustentável da empresa através de sua embalagem. Diante do resultado, podemos apontar que os produtos que possuem uma utilidade aliada à organização, como caixas de diversos tamanhos, porta trecos, divisória de gaveta, além de produtos que atendam o público infantil, foram os mais citados.

Podemos concluir a primeira etapa de forma positiva e desafiadora, onde $72 \%$ dos participantes responderam que reaproveitaram a embalagem de caráter sustentável, e ainda encontrou uma utilidade para o produto impresso. Portanto, segundo as análises do questionário, comprova que a experiência de montar o produto sustentável foi satisfatória e aliado aos depoimentos registrados na pesquisa concluímos que o redesign é necessário e bem aceito por seu público-alvo.

\section{RESULTADO DOS PONTOS-CHAVE}

\section{Conhecendo o Produto}

A empresa Meu Móvel de Madeira não possui um parque fabril, por isso, conta com cerca de 20 empresas moveleiras da região do Planalto Norte Catarinense para o processo de fabricação e fornecimento dos móveis disponibilizados em seu comércio eletrônico. A Móveis Serraltense de São Bento do Sul - SC, é a empresa responsável pela fabricação da Escrivaninha Duna 120 nos acabamentos expresso, cerezo e branco laqueado para a venda exclusiva no comércio eletrônico, conforme ilustra a figura 02.
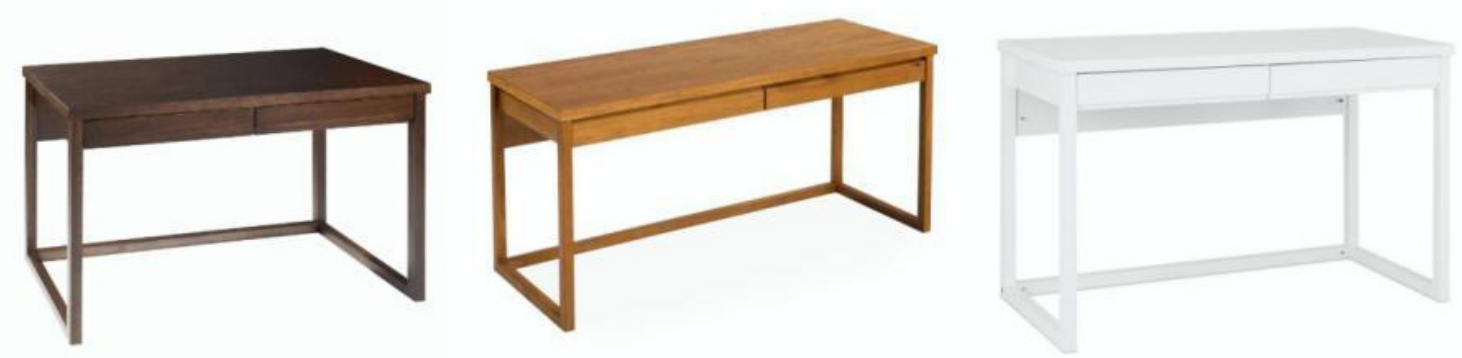

Figura 02: Modelos da escrivaninha duna 120

Fonte: Meu Móvel de Madeira (2013)

Para melhor conhecer o produto e suas características, o mesmo foi analisado 
através da montagem do produto na empresa e registrado com fotografias. Todavia, consideramos que é o momento mais importante que existe entre a empresa e o cliente, ou seja, o contato e a sua experiência com a montagem definirão o grau de satisfação, fidelidade e engajamento para então tomar a decisão de montar também o produto com caráter sustentável impresso no interior da embalagem. Salientamos que a empresa disponibiliza a opção de contratação de montagem junto à finalização do pedido, que pode ser um obstáculo para a embalagem ser descartada ao invés de ser reaproveitada.

Uma das etapas que enfatizamos neste projeto é a visão do interior da embalagem. Na tampa podemos conferir a impressão das embalagens com caráter sustentável denominado de "surpresinha". Logo estão acondicionadas as peças do móvel, junto do manual de montagem, termo de garantia e folha amarela que comunica a surpresinha. A caixa de ferragens possui uma fita vermelha que sai de seu interior para informar a existência do pacote de ferragem, e sua estrutura de papelão auxilia na proteção do móvel, detalhes podem ser observados na figura 03.

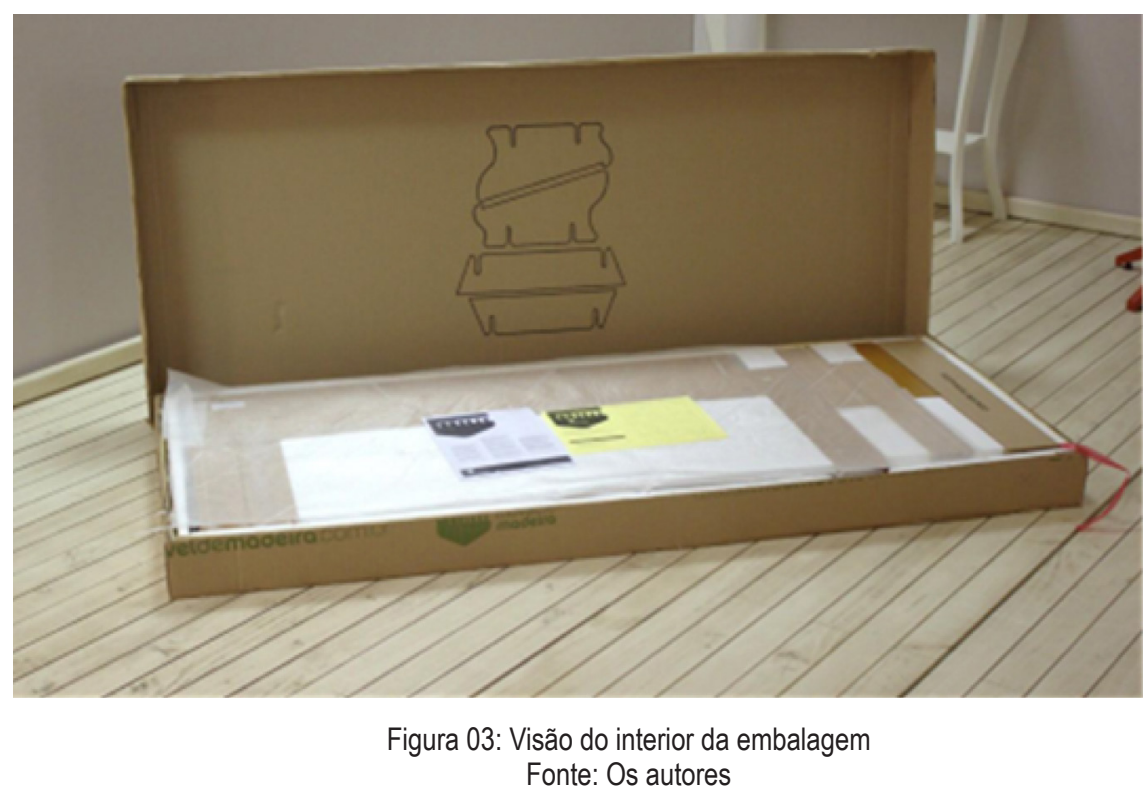

Observamos que a embalagem continha em seu interior o suporte para notebook, onde foi impresso em apenas uma das faces da caixa, não aproveitando portanto, a área total. Através de conversas com os inspetores de qualidade da empresa, concluímos que atualmente não existe um controle de impressão rotativo, que alterne portanto, o produto impresso no interior da embalagem, ficando a escolha da empresa terceirizada fabricante das embalagens, a escolha da impressão dos produtos denominados de surpresinha, e que em muitos casos é sempre o mesmo devido a comodidade e agilidade no processo de produção.

\section{Conhecendo o Consumidor}

Segundo a média dos meses de junho, julho e agosto de 2013, do relatório de avaliação do E-bit, podemos traçar um importante perfil do consumidor da Meu Mó- 
vel de Madeira:

$76 \%$ do público-alvo da empresa são do sexo feminino

$39 \%$ do seu público-alvo possuem entre 35 e 49 anos e 21\% possuem entre 55 e 64 anos;

$37 \%$ possuem curso superior e $32 \%$ pós-graduação;

$23 \%$ dos clientes possuem uma renda entre $\mathrm{R} \$ 3.001$ a $\mathrm{R} \$ 5.000$ reais e $19 \%$ entre $\mathrm{R} \$ 5.001$ a $\mathrm{R} \$ 8.000$ reais.

Ainda, para complementar o perfil do público-alvo da empresa, consultamos a ferramenta Navegg Analytics, onde 38\% do seu público feminino possui entre 35-59 anos e pertencem a classe C. Ainda, $16 \%$ do público feminino possui entre 25-34 anos e também pertence à classe $C$. Ficando evidente que a empresa possui um público essencialmente feminino, com faixa etária entre 35-59 anos, graduada do ensino superior, solteira e pertencente a classe $C$.

\section{Conhecendo o Mercado}

A produção da indústria de embalagem apresentou uma retração de $-1,47 \%$ em 2014, segundo o estudo a produção foi influenciada pelo desempenho econômico do país, para 2015 o cenário tende a apresentar uma retração de - 0,5\% na produção física de embalagem, resultado das dificuldades econômicas do país (ABRE, 2015). Embora o setor de papel, papelão e cartão tenha apresentado uma retração em sua produção de - 0,70\% em 2014, o setor ainda corresponde a 40,5\% de participação do segmento na indústria de embalagem no Brasil, permanecendo como líder do mercado de embalagem (ABRE, 2015).

\section{Conhecendo a Concorrência}

A análise de concorrentes ocorreu entre agosto e setembro de 2013, e durante este período não foram encontradas referências de empresas brasileiras que realizavam venda de móveis em lojas físicas ou através da internet, com iniciativas sustentáveis de reaproveitamento das embalagens.

Conforme constatado em conversa com a empresa, a ideia de reaproveitar as embalagens de papelão foi iniciada após conhecerem os produtos da empresa Jaya! Design $^{6}$, da designer gráfica, ilustradora e fundadora Sabrina Arini de Porto Alegre RS (vide figura 04).

${ }^{6} \mathrm{http}: / / j a y a d e s i g n . c o m \cdot b r$ 

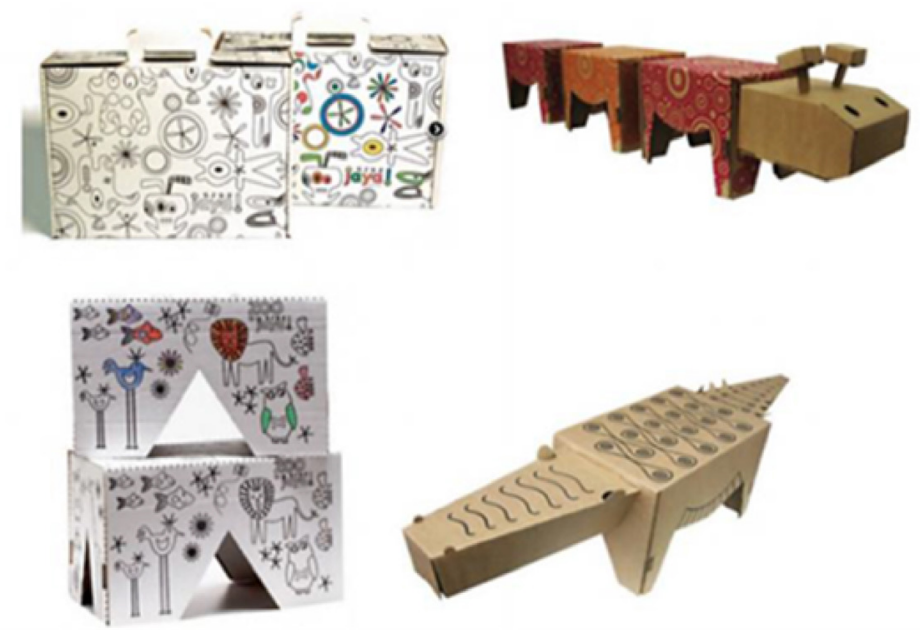

Figura 04: Exemplo de reaproveitamento de embalagens Fonte: Jaya design (2013)

A Jaya! Design (2013) é um estúdio que produz objetos em papelão serigrafado, e "veio ao mundo aos pouquinhos. Um colorido aqui, um produto diferente ali, um papelão acolá. Pouco a pouco, coleção por coleção, ela foi construindo um universo todo especial". E assim, inspirados por esta empresa a Meu Móvel de Madeira desenvolveu seus primeiros modelos, que não sofreram nenhum tipo de modificação ou releitura ao longo dos anos. A Gerente de Entretenimento apresentou como fonte de inspiração a empresa Holandesa, Joolz que fabrica produtos destinados para pais e bebês, em 2005 começou a inserir instruções para as impressões na embalagem do produto.

Além disso, durante as pesquisas de produtos sustentáveis em papelão constatamos que existem atualmente no mercado inúmeros exemplos de reaproveitamento de embalagens de forma sustentável, aliado ao design, inovação e a criatividade, conforme a figura 05.
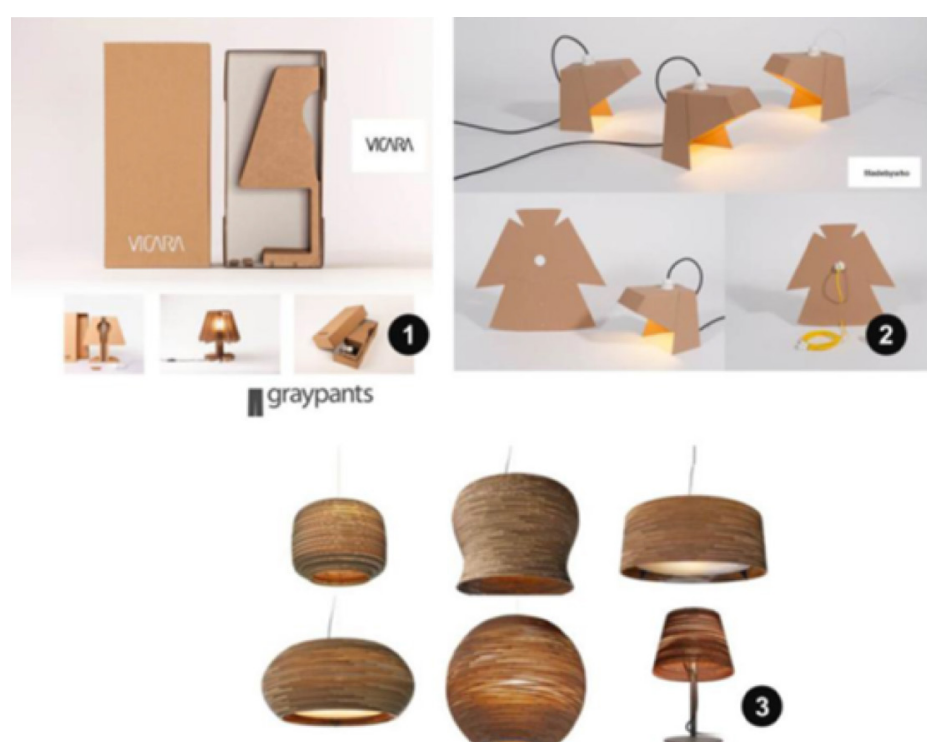

Figura 05: Exemplo de produtos sustentáveis em papelão

Fontes: Exemplo 1: Vicara (2013) | Exemplo 2: Madebywho (2013) | Exemplo 3: Graypants (2013)

\section{Conhecendo Tecnicamente a Embalagem a ser Desenhada}

Para compreender o processo produtivo da embalagem do produto escolhido 
para este projeto, a Meu Móvel de Madeira envia a empresa fornecedora do móvel, neste caso à Móveis Serraltense, um manual por e-mail no formato pdf que contém todas as especificações de impressão das embalagens, o modelo do manual de montagem do produto, o padrão das etiquetas e locais de aplicação nos móveis. A Móveis Serraltense por sua vez é responsável pela fabricação do móvel, e também contrata o serviço de uma empresa especializada em embalagens (Nova Embalagens), solicitando em seguida a produção de embalagens de acordo com o padrão exigido pela Meu Móvel de Madeira.

Em visita técnica realizada na empresa Nova Embalagens, em São Bento do Sul - SC, verificamos que existe um estoque diverso de chapas de papelão dos mais diversos tipos e tamanhos. Quando aprovado o layout da caixa pelo cliente, é iniciado o processo de transformação da chapa em caixa de papelão, e isto é realizado pela máquina denominada no ramo de embalagens de vincadeira.

Em posse da embalagem, a empresa fabricante do móvel embala, separa as ferragens, a impressão do manual de montagem e da comunicação do produto. Em seguida, a empresa aplica as etiquetas por fora da embalagem conforme as especificações padrão da Meu Móvel de Madeira e aguarda a inspeção do lote para que seja liberada ao centro de distribuição.

6. Conhecendo os Objetivos Mercadológicos

Os atuais produtos de caráter sustentável desenvolvidos e impressos nas embalagens da Meu Móvel de Madeira não sofreram alterações desde o ano de 2009, que começou a ser impressa e presenteada a seus clientes. Além disso, com o auxílio do questionário comprovou que o cliente acredita nesta atitude, portanto merece um redesign. E para tal, os objetivos mercadológicos da Meu Móvel de Madeira em relação a atitude sustentável são:

Explorar no comércio eletrônico, uma página especial, informações que divulguem esta iniciativa e detalhes;

Divulgar as embalagens sustentáveis através de e-mails marketing;

Produzir vídeos com a temática da sustentabilidade relacionando a sua embalagem e a montagem dos novos produtos sustentáveis;

Desenvolver uma marca própria para as embalagens sustentáveis;

Criar coleções da nova marca;

Possibilitar futuramente que estes produtos possam ser vendidos em seu site, assim como os móveis e sua linha de decoração;

Adotar as soluções sugeridas para o acondicionamento das ferragens;

Alternar as impressões dos produtos no interior da embalagem para que não se repitam conforme acontece hoje;

Escolher os produtos que possuem uma maior rotatividade, para serem aplicados os novos produtos de caráter sustentável.

7. A estratégia para o Design

Optamos para o projeto a estratégia que prima pelo conceito de consumo verde, aquele em que o consumidor, além de buscar melhor qualidade e preço, inclui em seu poder de escolha, a variável ambiental, dando preferência a produtos e serviços que não agridam o meio ambiente, tanto na produção, quanto na distribuição, no consumo e no descarte final (MINISTÉRIO DO MEIO AMBIENTE, 2005). 
Também, no decorrer deste projeto em conversas com especialistas e envolvidos no assunto da Meu Móvel de Madeira, ainda funcionários da Móveis Serraltense e da empresa Nova Embalagens, ficou evidente que existem dois paralelos neste projeto, o desejo de colocar em prática ideias inovadoras para os clientes, contra as limitação de orçamento e margem de lucro das empresas envolvidas.

O desafio da estratégia de design para este projeto está, portanto, em conciliar os paralelos entre a indústria e o consumidor, a fim de beneficiar ambos os lados, em prol de um consumo consciente e de um mundo mais sustentável em pequenas atitudes.

\section{Desenhando de Forma Consciente}

Durante as pesquisas e análises das atuais embalagens e do modo de acondicionar as ferragens notamos que as embalagens desenvolvidas em 2009, não exploram o uso de grafismos, nem a possibilidade de criar uma marca própria para as caixas sustentáveis, podendo ainda, possuir conceitos baseados em temas relacionados com a iniciativa. Por este motivo decidimos desenvolver uma linha de produtos e soluções que apresente uma proposta gráfica paralela à marca e ao perfil dos consumidores da empresa, aliado ao design de embalagem e ao consumo consciente sustentável.

Para auxiliar no desenvolvimento dos produtos de caráter sustentável, foram construídos primeiramente painéis de caráter semântico, de inspiração, e do público -alvo (vide exemplo na figura 06), os novos produtos deverão possuir um sentido de praticidade e utilidade para seus usuários, bem como apresentar características lúdicas que identifiquem junto ao tema uma identidade para as embalagens sustentáveis, e alie ainda o conceito geométrico.

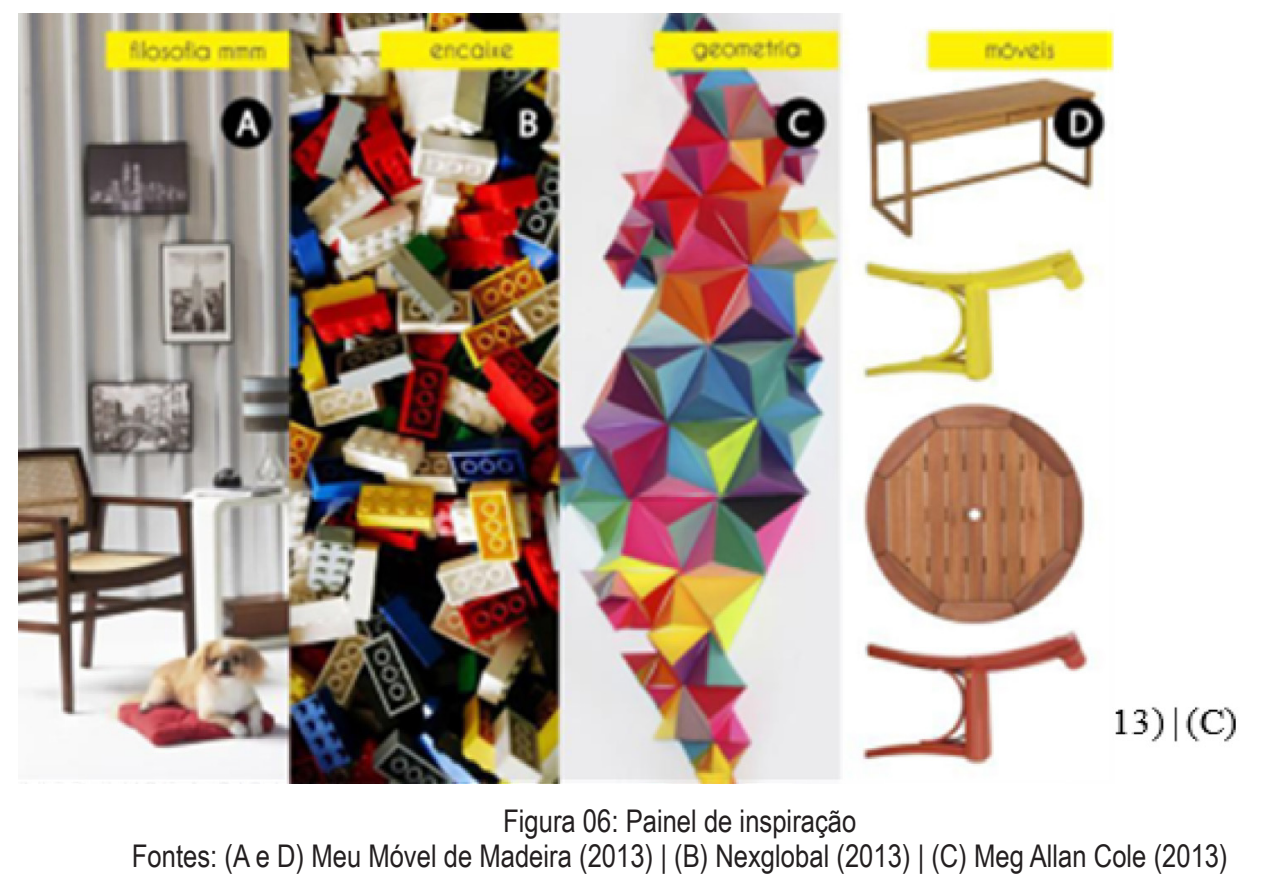

Na sequência, com os desenhos técnicos planificados foi possível testar a utilidade das embalagens e sua forma, a fim de corrigir erros de construção e validar as alternativas escolhidas junto à empresa e a fabricante das embalagens. Foi possível neste momento compreender as limitações da embalagem classificada como onda 
dupla, o que não confere muita maleabilidade ao material, impossibilitando assim a construção de inúmeras opções para o reaproveitamento.

A próxima etapa foi destinada a construção do grafismo, que deverá caracteriza as novas embalagens de caráter sustentável e confere mais destaque e valor para o público-alvo, tendo como referências os painéis construídos anteriormente (vide figura 07).

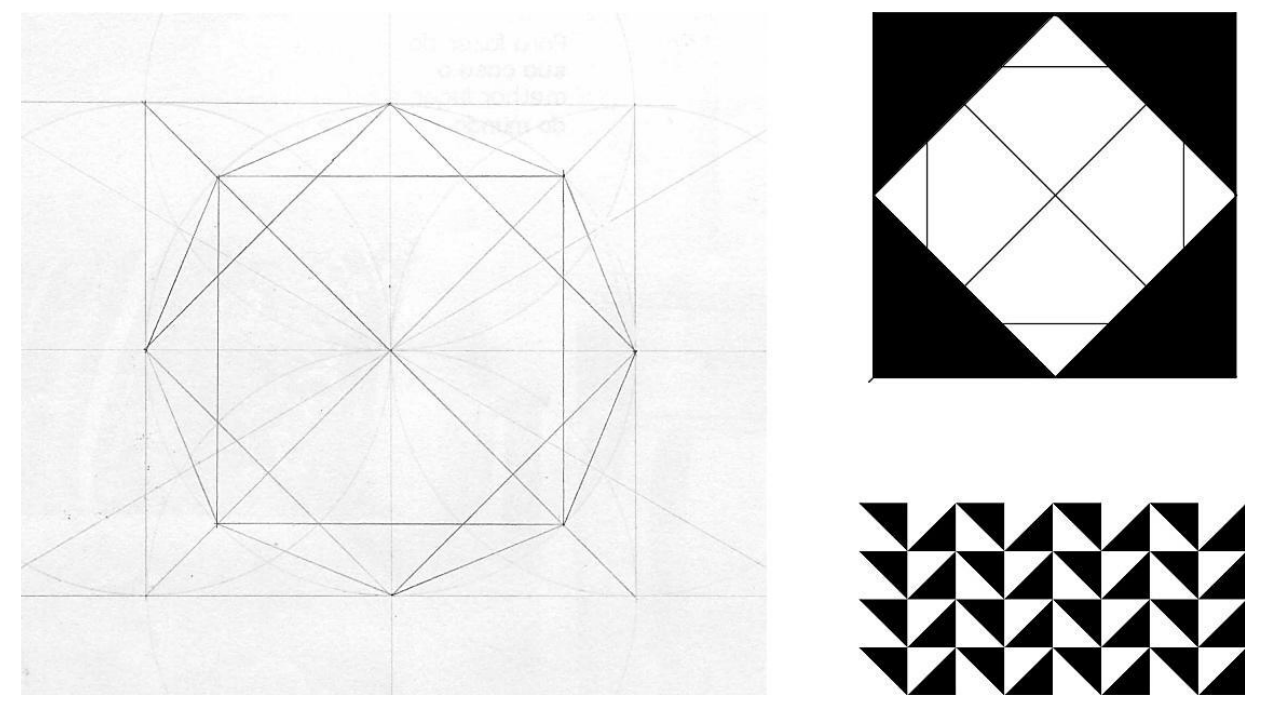

Figura 07: Construção do grafismo

Fonte: Os autores

Para finalizar a etapa de desenho de forma consciente, escolhemos a melhor alternativa de grafismo e aplicamos nas embalagens definidas para este projeto, que foram uma caixa com alça, uma divisória de gaveta, um porta celular, e um jogo com três caixas denominadas de porta-trecos. Os desenhos técnicos e a aplicação final das embalagens sustentáveis, bem como sua aplicação para o reaproveitamento das faces da embalagem da empresa estão exemplificadas a figura 08. 

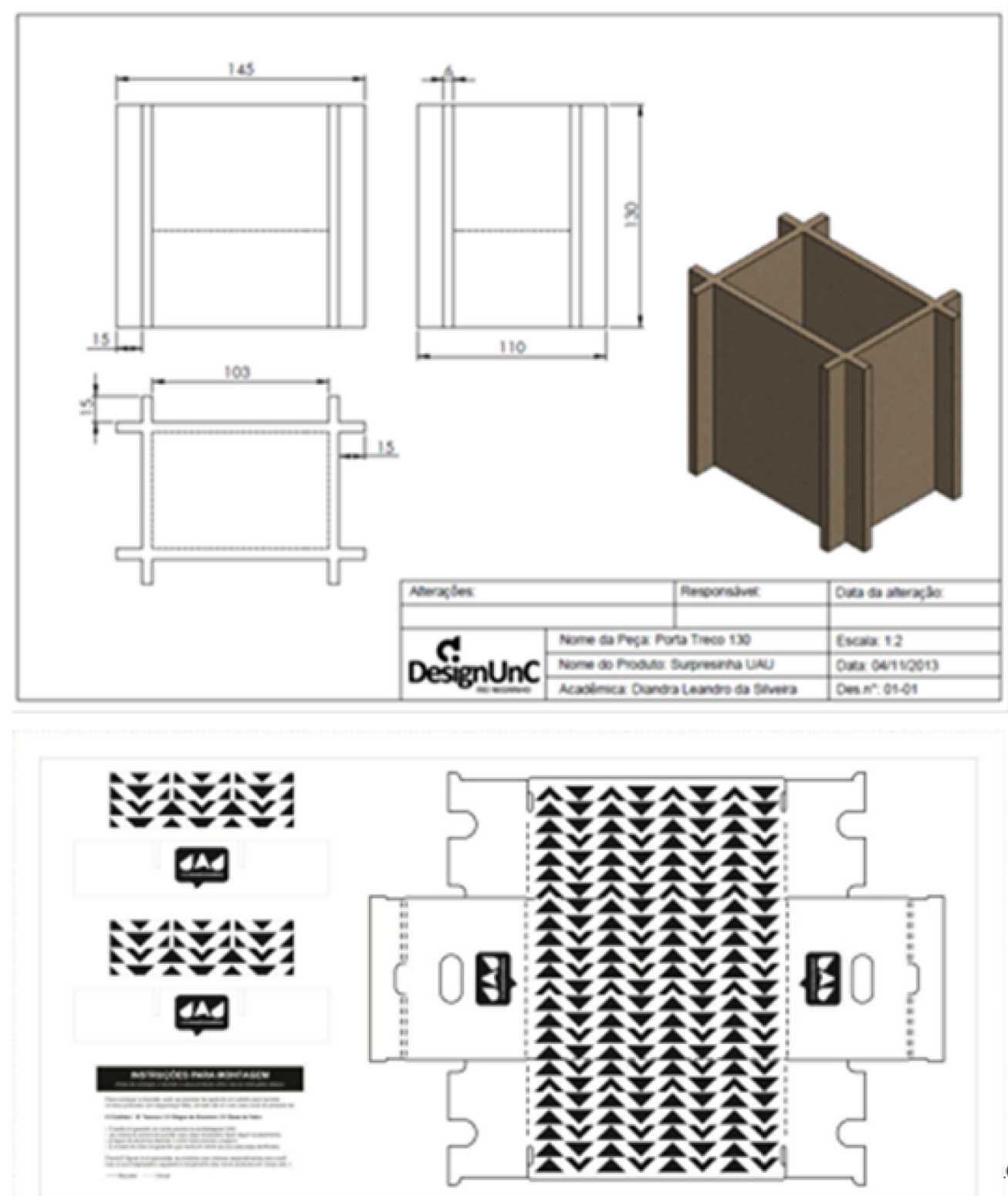

0

Figura 08: Exemplo do desenho técnico e planificação com o grafismo escolhido. Fonte: Os autores

E por fim, definimos que para o acondicionamento das ferragens a melhoria sugerida está apenas no aumento das etiquetas classificadas por letras que são utilizadas na identificação de cada ferragem de acordo com as peças indicadas no manual de montagem. Por isso, foi definido que o novo padrão das letras impressas deve seguir o tamanho 20x20 milímetros, sendo que a letra deve estar com fonte Arial no tamanho de 40 pontos para impressão colorida e/ou p\&b.

9. Trabalho Integrado com a Indústria

Com a troca de experiências junto à indústria é possível conhecer as dificuldades e qual a melhor forma de trabalhar com o desenvolvimento e preparação dos desenhos técnicos, detalhes, especificações, materiais e padrões a utilizar no projeto.

A empresa Nova Embalagens foi responsável em produzir os protótipos deste projeto. A mesma realizou a preparação e desenvolvimento das chapas de onda dupla 
com espessura de seis milímetros, conforme o padrão das embalagens da Meu Móvel de Madeira para que fosse recortada, sem a intervenção de facas de corte prontas ou máquinas no processo de construção/montagem das novas embalagens. Em resumo, foram cortadas da mesma forma que um cliente da Meu Móvel de Madeira faria em sua casa, utilizando de materiais simples e sem complicações.

10. Revisão do Projeto

Devido a extensão abrangência da Meu Móvel de Madeira, fica financeiramente inviável, para visitar pessoalmente os clientes e avaliar se de fato, as melhorias propostas com este projeto estão a contento.

Assim, foi definido junto a empresa que a maneira mais eficaz de medir o nível de satisfação em relação ao redesign das embalagens sustentáveis será através de pesquisas constantes, sob a forma de feedback contínuo utilizando as ferramentas de mídia da empresa, como e-mail marketing, pesquisa de satisfação, entre outros.

\section{RESULTADO DA ESTRATÉGIA DE IDENTIDADE E DIVULGAÇÃO}

Com o intuito de fortalecer a identidade deste projeto de redesign de embalagem foi construída uma identidade visual baseada no primeiro valor da empresa: "Transmita UAU", que vem a significar a busca de algo diferente. Desta forma, tendo também como conceito a geometria dos móveis e das características marcantes de uma embalagem, bem como, conhecendo as limitações relacionados a viabilidade de custo, criamos traços mais retos e adotamos apenas uma cor para a marca.

Além das mídias, definidas como uma tag indicativa que será contemplada junto a face externa da embalagem para orientar o cliente antes da abertura da caixa sobre o seu conteúdo e devidos cuidados, desenvolvemos uma ecobag para servir como brinde e embalagem para os produtos UAU adquiridos no site da empresa. Agregado a esse etapa do projeto, criamos materiais iniciais da campanha para divulgação da marca UAU e seus produtos como um e-mail marketing, banner para redes sociais e uma página especial que servirá como canal de vendas para se obter os produtos através do comércio eletrônico. O resultado desta estratégia, está exemplificado a seguir, na figura 09. 

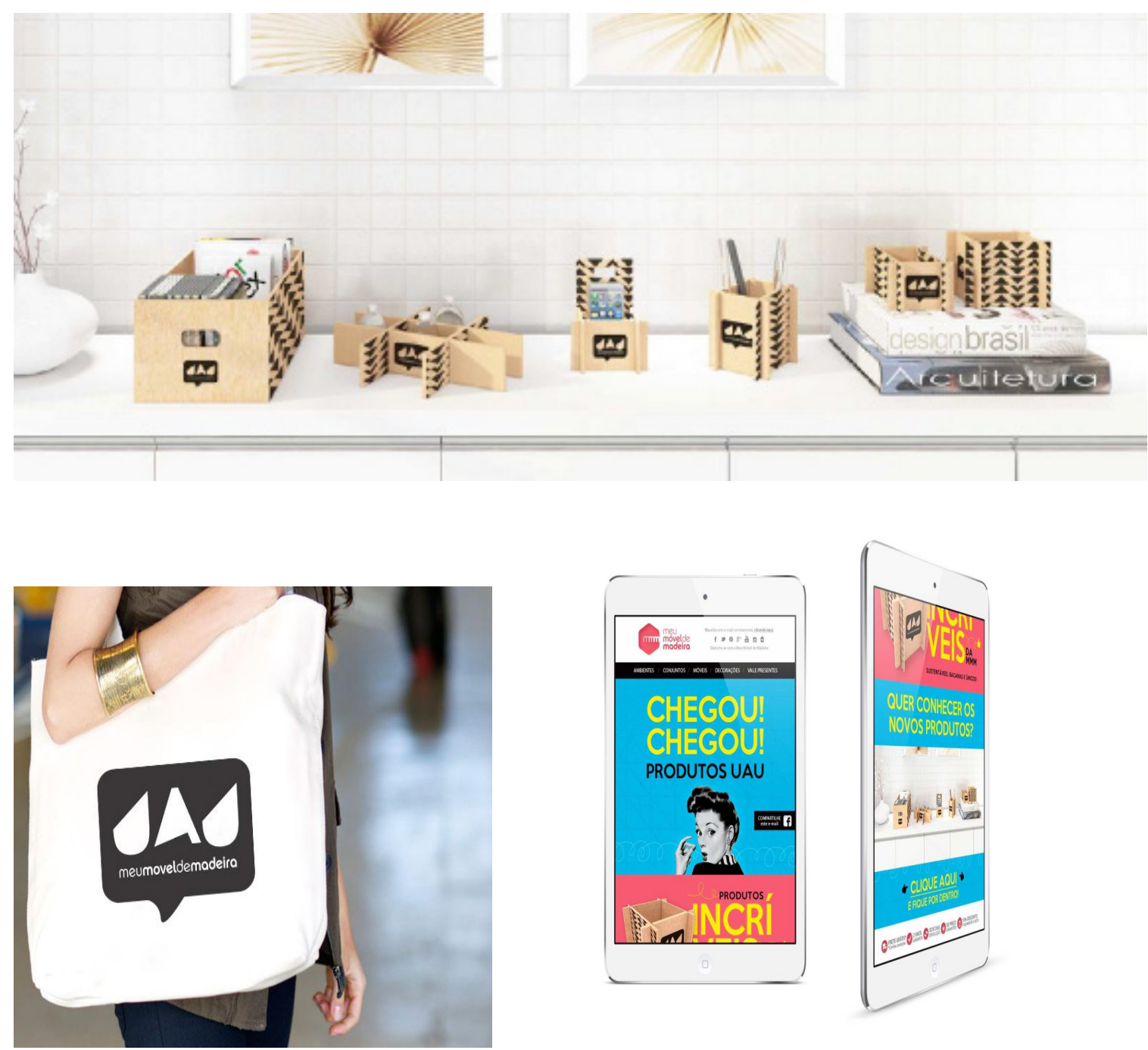

Figura 09: Exemplos da marca e mídias Fonte: Os autores

\section{RESULTADO DAS ANÁLISES DAS FUNÇÕES}

Definimos neste ponto que as funções práticas das embalagens sustentáveis possuem a essência de reaproveitar, organizar e entreter. Para o acondicionamento das ferragens definimos que as funções práticas são de informar, proteger e auxiliar a montagem do móvel.

Como função estética, definimos que as embalagens sustentáveis são temáticas, práticas e inovadoras no mercado de móveis online. Para o acondicionamento de ferragens definimos que a função estética está na praticidade, simplicidade e transparência. E por fim, a função simbólica das embalagens sustentáveis estão nas formas geométricas, conceitual e exclusiva, enquanto no acondicionamento das ferragens está na ligação com as experiências e sensações, definimos como algo trivial, passageiro e comum, porém, personalizado, pois possui um grande diferencial em relação aos seus concorrentes. 


\section{CONCLUSÕES E DESDOBRAMENTOS DA PESQUISA}

O mercado está aberto à proposta iniciada em 2009 pela Meu Móvel de Madeira, porém observamos uma grande oportunidade de melhoria no desenvolvimento de novos produtos que atendam aos desejos e necessidades dos consumidores da empresa. Sendo assim, definimos como objetivo do projeto agregar valor e apresentar variações dos impressos gráficos nestas embalagens reutilizáveis anualmente devido a viabilidade de custo benefício desta iniciativa, tanto para a empresa, quando para seus fornecedores e clientes.

Este projeto oportunizou conhecer mais tecnicamente o universo da embalagem, uma área até pouco tempo desconhecida em sua totalidade.

A empresa Nova Embalagens foi extremante prestativa e gentil, e garantiu informações preciosas para o bom desenvolvimento do projeto em sua construção e execução. Bem como, foi importante a participação dos clientes usuários da embalagem que contribuíram para melhor avaliar e atingir os objetivos deste projeto.

O desenvolvimento de uma marca e suas formas de exibição serviu para reforçar e fortalecer a importância do projeto para com a defesa de preservação do meio ambiente.

O acondicionamento das ferragens necessitou pequenos ajustes e defesa de padrões para melhorar a comunicação e clareza das informações. A aplicação de grafismos na embalagem que acondiciona as ferragens devido à grande variação de tamanhos impossibilitou seu reaproveitamento, mas garantiu a qualidade e respeito pelo transporte e montagem do móvel adquirido por qualquer consumidor residente no território brasileiro.

Observamos ainda a oportunidade de revisão e melhoria dos manuais de montagem da Meu Móvel de Madeira, onde deverá ser criado um padrão a ser seguido por seus fornecedores, assim como a revisão dos materiais de etiquetas e sua aplicação.

Deste modo, podemos concluir que o objetivo geral de analisar e desenvolver através do reaproveitamento de embalagem, o redesign dos produtos impressos nas caixas de papelão, bem como, melhorar as informações e a estética do acondicionamento das ferragens da Escrivaninha Duna 120 foi concretizado com êxito.

Dentre os objetivos específicos escolhidos, podemos relatar que conhecemos a fundo e analisamos tecnicamente a embalagem e o acondicionamento das ferragens da Escrivaninha Duna 120. Verificamos que a reutilização da embalagem é aprovada pelo consumidor da empresa. Em seguida, realizamos o redesign da embalagem com princípios focados na sustentabilidade e no reaproveitamento do material seguindo duas metodologias de design.

Por fim, sugerimos melhorias e desenvolvemos uma estratégia de identidade para a divulgação do redesign da embalagem perante o mercado. Como desdobramento, será necessário validar com os consumidores a aprovação do redesign e a atitude do reaproveitamento da embalagem. 


\section{REFERÊNCIAS}

ABRE (2013a). Embalagem. Disponível em: <http://www.abre.org.br/setor/apresentacao-do-setor/a-embalagem>. Acesso em: 02 out. 2013.

ABRE (2013b). Sustentabilidade. Disponível em: <http://www.abre.org.br/setor/apresentacao-do-setor/a-embalagem/sustentabilidade/>. Acesso em: 02 out. 2013.

ABRE (2015). Estudo Macroeconômico da Embalagem ABRE/FGV. Sessão O Setor. Disponível em: <http://www.abre.org.br/setor/dados-de-mercado />. Acesso em: 07 abr. 2015.

CAMARGO, L. N. F. et al. O Papel Social do Design Visando a Sustentabilidade, Actas de Diseño. Facultad de Diseño y Comunicación. Universidad de Palermo, 2007.

COLE, Meg Allan. 3D Geometric Wall Sculpture-Sm. Make. Disponível em: <http:// makezine.com/craft/paper-triangle-web/3d-geometric-wall-sculpture-sm/>. Acesso em: 14 out. 2013.

GRAYPANTS. Products. Disponível em: <http://shop.graypants.nl/>. Acesso em: 08 nov. 2013.

HILSDORF, C. O que é benchmarking? Disponível em: <http://www.administradores. com.br/artigos/administracao-e-negocios/o-que-e-benchmarking/48104/>. Acesso em: 16 jun. 2013.

JAYA DESIGN. Sessão Quem Somos. Disponível em: <http://jayadesign.com.br/linhajaya-catalogo/content/6-quem-somos>. Acesso em: 08 out. 2013.

LÖBACH, B. Design Industrial: Bases para a configuração dos produtos industriais, 1. ed. São Paulo: Edgard Blücher, 2001.

MADEBYWHO. My Lamp. Disponível em: <http://www.madebywho.dk/mylamp/>. Acesso em: 08 nov. 2013.

MEDEIROS, I. Sobre a discussão estética vs. Usabilidade. Disponível em: <http://webinsider.com.br/2002/11/20/sobre-a-discussao-estetica-vs-usabilidade/>. Acesso em: 13 nov. 2013.

MESTRINER, F. Design de Embalagem - Curso Básico, 2a ed. São Paulo: Pearson Makron Book, 2002.

MEU MÓVEL DE MADEIRA. Disponível em: <http://www.meumoveldemadeira.com. br>. Acesso em: 16 mai. 2013.

MINISTÉRIO DO MEIO AMBIENTE. Consumo sustentável: manual de educação. Brasília: Consumers International/ MMA / MEC / IDEC, 2005.

MOZOTA, B. B. D.; KLÖPSCH, C.; COSTA, F. C. X. D. Gestão do Design - Usando o Design para Construir Valor de Marca e Inovação, Porto Alegre: Bookman, 2003.

NETQUEST. A escala Likert - Coisas que todo pesquisador deveria saber. Disponível em: <http://www.netquest.com/br/blog/a-escala-likert-coisas-que-todo-pesquisador-deveria-saber>. Acesso em: 10 jun. 2013.

NEXGLOBAL. La innovación requiere creatividad. Nexglobal Comunicación y Marketing Integral. Disponível em: <http://www.nexglobal.es/2013_01_01_archive.html>. Acesso em: 14 out. 2013.

OLIVEIRA, L. G. R.; MORAES, M. F. V. D. O consumo consciente de embalagens sustentáveis. IV Congresso Internacional de Pesquisa em Design, Rio de janeiro, 11 à 13 
de Outubro, 2007.

PELLEGRINO, L. Embalagem: A Embalagem nos dias de hoje. ABRE. Disponível em: <http://www.abre.org.br/setor/apresentacao-do-setor/a-embalagem>. Acesso em: 23 out. 2013.

VICARA. Disponível em: <http://www.vicara.org/>. Acesso em: 02 nov. 2013. 